\title{
UNDERSTANDING MEANING AND BRIDGING DIVIDES: The Use of an African Metaphor for the South African Open Source Center
}

\author{
Elaine Byrne \\ University of Pretoria \\ Tshwane, South Africa \\ Bob Jolliffe \\ University of South Africa \\ Tshwane, South Africa \\ Nhlanhla Mabaso \\ Meraka Institute \\ Center for Scientific and Industrial Research \\ Tshwane, South Africa
}

\begin{abstract}
This paper describes a conscious attempt to use metaphor to both promote and reinterpret ideas and values from the global free and open source software movement in the context of South Africa. A case study is given of an initiative launched by the South African Council for Industrial and Scientific Research to stimulate awareness and promote the use of free and open source software in South Africa and the region. The new Open Source Center made use of an African language metaphor to relate the concept of shared intellectual property in software to traditional communal land management. Whereas Western metaphors are commonly used in the field of organizational studies and Information Systems to facilitate meaning, the deliberate use of an African language metaphor to describe software systems is less common (even in Africa). This paper provides a background as to why such a metaphor was chosen as well as some reflection on its effectiveness.
\end{abstract}

Keywords Metaphors, open source software, free software, South Africa

Please use the following format when citing this chapter:

Byrne, E., Jolliffe, B., and Mabaso, N., 2006, in IFIP International Federation for Information Processing, Volume 208, Social Inclusion: Societal and Organizational Implications for Information Systems, eds. Trauth, E., Howcroft, D., Butler, T., Fitzgerald, B., DeGross, J., (Boston: Springer), pp. 279-293. 


\section{INTRODUCTION}

Most of us who are connected in some or other way to the field of Information Systems share a roughly common understanding of what software is. Many of us will recall early courses in computer literacy where terms like hardware and software were introduced. At the risk of some inaccuracy, we might say that software refers to the programs which execute on programmable computers, or hardware. Though the terminology is far from intuitive, particularly to the large majority of people who would not be classified as "computer literate," we feel that, given access to a computer and its programs, the term software can be reasonably easily explained and understood.

There has been considerable interest in recent years in a "species" of software which is variously referred to as open source software, free software, free/open source software (FOSS) and even free/libre/open source software (FLOSS). The choice of terminology is somewhat contested, reflecting, as we shall see below, different political or philosophical strands within the communities of practitioners, users, and developers who create and sustain the software. Without wishing to pass judgment on any of these positions we will proceed in this discussion using the term FLOSS. It has been the experience of the authors that a significant majority of people (even those who understand what software is) find the concept of FLOSS counterintuitive, confusing, and, at least at first pass, unconvincing. This situation is not improved by the lack of clear consensus on terminology and approach within the FLOSS "movement."

These difficulties would not be worthy of much discussion, except that it is widely believed that this "stuff" has some merit and that it may even have an important role to play in the development of a more open, equitable, affordable, and empowering vision of an information society. In 2002 in South Africa, the National Advisory Council on Innovation (NACI) ${ }^{1}$ produced a report entitled "Open Software and Open Standards-A Critical Issue for Addressing the Digital Divide," in which this view was clearly articulated. The decision to set up a center in 2003 to promote and support the adoption and development of FLOSS within South Africa and the region was an outcome of the NACI report. Two of the authors of this paper were involved in the initial setup phase of the project. One of the authors continues to be the manager of this center.

Our early experience of FLOSS advocacy indicated that explaining FLOSS to key decision makers, who had been thoroughly immersed in a dominant narrative of software as exclusively private intellectual property, was a nontrivial task. What was needed was a metaphor.

This paper illustrates how metaphors can be used in organizational change and how the use of a particular metaphor $\left(\right.$ meraka $\left.^{2}\right)$ was used strategically to effect such a change in the Open Source Center (OSC) at the Center for Scientific and Industrial Research (CSIR) in South Africa. The use of a common concept from everyday life helped over-

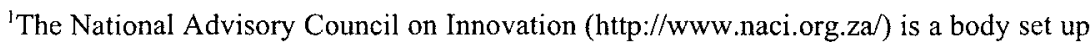
by a South African Act of Parliament to advise the then Minister of Arts Culture Science and Technology, as well as the Cabinet as a whole, on science and technology issues.

${ }^{2}$ Meraka is a term used in Lesotho, South Africa, and Botswana to describe common grazing land. People may engage in private or communal productive activity on this land, but the land itself is kept for the common good. Its use in Botswana has been described by Arntzen (1989). 
come some of the difficulties with explaining and understanding the concept of FLOSS beyond the software community. This particular metaphor supported the desire by the management for an African image for the Center, while at the same time bringing to the forefront some of the resistance and difficulties in pursuing this image.

To place the case study and its use of the metaphor meraka in context, we first describe briefly the common usage of metaphors in organizational change and Information Systems development literature. In section 3 we describe the current debate between the concepts of free and open source software. Section 4 introduces the case study of the OSC in the Meraka Institute, and section 5 presents a discussion of the case study in light of the previous debates presented in section 2 and 3 . In the last section, we conclude with the more general contributions that this paper makes.

\section{IS AND METAPHOR USE}

Metaphors are used in everyday life to facilitate meaning. For example, we commonly hear phrases such as "eating your words," "winning an argument," or "having a heart of stone." A metaphor is defined as "use of a word or phrase to indicate something different from (though related in some way to) the literal meaning" (Oxford Advanced Learner's Dictionary 1989). Metaphors can be seen as a symbol, a figure of speech, a simile, an image or an allegory. They help make sense of situations, help in understanding new concepts or existing situations. Metaphors help put meaning into experiences and are useful in balancing apparent paradoxes or contradictions (Ott 1989; pp. 29-30 quoted in Kendall and Kendall 1993, p. 150). In the case of FLOSS, we were looking for a metaphor to lend possible meanings to a complex concept in easy to understand terms. In this way it would serve many functions, in fact address Weaver's (1967, quoted in Kendall and Kendall 1993, p. 150) four main functions of metaphors: supplying concreteness or actualization of an abstract idea, clarifying the unknown, expressing the subjective, and assisting thought. Meraka was the metaphor chosen.

The potential for metaphors within organizations and IS have long been recognized. The use of metaphors to maintain or change the organizational culture is a common theme in organizational literature. It is also a way of knowing the principle ways in which people endow experience with meaning. Although in relation to narratives Ramiller notes (2001, p. 290) that

a story never really "tells itself." In finding meaning in a narrative the listener also draws on personal experience, cultural convention, and knowledge of the social context to which the narrative refers-plus a learned facility with the task of interpreting stories.

Metaphors can be used in a similar way.

\subsection{Organizational Studies and Metaphors}

Krefting and Frost (1995) argue that in addition to capturing the complexity of an organization in the members' own terms "metaphors may also serve in grasping an 
existing culture, framing a new culture, or generating change where current organizational culture is perceived to be less than optimal" (p. 158). They investigate how culture in organizational settings can be managed through the therapeutic use of metaphors using two constructs: the degree of heterogeneity (homogeneity) and location of blockages (conscious-unconscious). Krefting and Frost endorse the use of metaphors in situations of organizational change: "Metaphors may serve as models or paradigms that can help focus attention on what currently exists, frame other possibilities where change is perceived as desirable, and initiate action towards such change" (p. 168).

Walsham (1993, p. 37) comments on how little work has been done on subcultures and metaphors within organizations. One exception to this is the work by Young (1989), in which the author shows how the symbol of the rose within an organization was viewed as having a fixed meaning by management, but in fact hid the different feelings and loyalties of two main groups of shop floor workers in a textile company. Thus the same symbol or metaphor can have very different meanings within an organization. Young concludes that, "It is this tension between fragmentation and unity which I argue is the organizational culture, while the symbols, artefacts, myths, etc., informing organizational events are the explicit manifestation of it" (pp. 203-204).

Walsham uses metaphors in an interesting way to understand the process of change within an organization. Using the metaphors of power and culture, the political metaphor encourages us to see organizations as loose networks of people with divergent interests who gather together for the sake of expediency (Morgan 1986). Power is viewed as a medium through which conflicts are resolved. Foucault saw the panoptican as a metaphor for modern society. Walsham concludes his discussion of metaphors:

Metaphors can also assist with the linking of academic practices with that of practitioners. Ramiller (2001) in his account of the Airline Magazine Syndrome shows how we can link academic literature with practical problems through the use of narratives. This is equally applicable to the use of metaphors. In this way, though challenging, metaphors can assist in some instances with combining the rationality of the academic world with the rationality of practitioners (Walsham 1993, p. 39).

In summary, within the organizational and management literature, metaphors have been used to understand or manage organizational culture; are the manifestation of the tensions between unity and fragmentation within an organization; assist with understanding the process of change; and provide a link between academic practices and the practices of practitioners.

\subsection{Information Systems and Metaphors}

Although there is no common or standard approach in the use of metaphors in systems analysis and design, metaphors have been used frequently in information systems literature (Hirschheim and Newman 1991; Walsham 1993). Walsham notes that the use of metaphors in information systems literature is mainly implicit, with the exception of Hirschheim and Klein (1989), who look at metaphors in terms of the alternative view of role of systems analyst, and Madsen (1989), who believes that we can consciously use metaphors. 
As information systems are social constructs, it is not surprising that there are a number of reasons why they are used in this field. Walsham (1993) and Hirschheim and Newman (1991) outline some of the reasons. Metaphors

- help liven up speech and writing;

- are an unexpected and creative device for evolving new images of known situations;

- build on the belief that our reality is defined through metaphors--metaphors are pervasive in everyday life (Lakoff and Johnson, 1980);

- are a way of thinking and seeing ("a way of thinking and a way of seeing that pervade how we understand our world generally," Morgan 1986, p. 12);

- $\quad$ are the ways we think and act (Boland 1987);

- $\quad$ provide fresh insight into existing situations with the use of new metaphors (Mangham and Overington 1987);

- can assist in tapping unconscious material in human minds (Krefting and Frost) 1995); and

- can facilitate change while maintaining stability (Pondy 1983).

Based on these reasons a number of common metaphors, such as war, journeys, and orchestra, are used in the field of information systems. A more comprehensive list of the metaphors used is given in Table 1.

The use of metaphors as indicated in Table 1 illustrate the various positive roles metaphors can play in IS development. However, from an information engineering perspective, Beath and Orlikowski (1994) show how the use of metaphors in IS development can, on one level, hide the underlying philosophy and motivation in user-involvement in IS development processes, but at another level reveal the true conscious or unconscious meaning behind the IS design techniques. The use of the metaphor player (either in an acting or sports context) fits in with the image of the developer of the IS being largely in control of the overall schema and the users participating in this plan. "Players participate on others' terms, in that the rules of the game or the script of the play are devised by and commanded by others (for example, game officials, umpires, coaches, playwrights, directors, and producers)" (Beath and Orlikowski 1994, p. 361). In the text they explored, Beath and Orlikowski discovered that "users seem to have little direct control over the nature and frequency of their contribution, the content and context of interaction, and the timing of events" (p. 361). They also came across the use of the missionary metaphor for systems analysts:

With this metaphor, the text implies that information technology is a religion, that analysts are priests, and that systems development methodologies are scriptures that will lead the heathens (the users) to their salvation. Users are unsophisticated "villagers," and their views are "folklore," hence, discountable. The analyst's job is to offer the users "a promise" of a better life.... In this claim the metaphor is quite accurate -although, one suspects, not in the way implied in the text - for missionaries' modus operandi is to convert the natives to their view of the world, rather than to try and accommodate the natives' views. In the referenced religious tradition, there is little modification of the faith by the converted (Beath and Orlikowski 1994, p. 361). 
Table 1. A Summary of the Use of Metaphors in Information Systems Literature

\begin{tabular}{|l|l|l|}
\hline \multicolumn{1}{|c|}{ Metaphor } & \multicolumn{1}{|c|}{ Use of Metaphor } & \multicolumn{1}{c|}{ Source } \\
\hline $\begin{array}{l}\text { War, organism, city- } \\
\text { state (society), and team } \\
\text { sports }\end{array}$ & $\begin{array}{l}\text { Metaphors are useful in enacting } \\
\text { corporate strategy and linking strategic } \\
\text { planning with IT planning. }\end{array}$ & $\begin{array}{l}\text { Mason } \\
(1991)\end{array}$ \\
\hline $\begin{array}{l}\text { Construction of the } \\
\text { palace of Versailles }\end{array}$ & A metaphor for IS design. & $\begin{array}{l}\text { Allen and } \\
\text { Lientz } \\
(1978)\end{array}$ \\
\hline $\begin{array}{l}\text { No common metaphors } \\
\text { suggested nor are meta- } \\
\text { phors investigated } \\
\text { which already are resi- } \\
\text { dent in systems develop- } \\
\text { ment methodologies }\end{array}$ & $\begin{array}{l}\text { Introducing metaphors in IS design rather } \\
\text { than discovering the metaphors which the } \\
\text { users rely on in their dialogue. }\end{array}$ & $\begin{array}{l}\text { Madsen } \\
(1989)\end{array}$ \\
\hline $\begin{array}{l}\text { Six main metaphors are } \\
\text { used: journey, war, } \\
\text { game, organism, society } \\
\text { and machine and; } \\
\text { three metaphors } \\
\text { emerged from the } \\
\text { language of IS users: } \\
\text { family, zoo and jungle }\end{array}$ & $\begin{array}{l}\text { Analysts who are aware of the existence } \\
\text { of metaphors will see systems develop- } \\
\text { ment process in a very different light. } \\
\text { Kendall and Kendall (1993) take } \\
\text { examples from various IS design ap- } \\
\text { proaches that fit the different metaphors } \\
\text { best-for example SDLC as a game; } \\
\text { structured methodologies and CASE tools } \\
\text { as a machine; prototyping as a journey; } \\
\text { project champion as the jungle; ETHICS } \\
\text { as a family; SSM as a zoo; multiview as a } \\
\text { society, and; IS development deteriorating } \\
\text { into war. }\end{array}$ & $\begin{array}{l}\text { Kendall and } \\
\text { Kendall } \\
(1993)\end{array}$ \\
\hline $\begin{array}{l}\text { Game, garden, } \\
\text { orchestra, journey and } \\
\text { machine }\end{array}$ & $\begin{array}{l}\text { Metaphors as a means of examining } \\
\text { phenomena from different angles. }\end{array}$ & $\begin{array}{l}\text { Gallupe } \\
(2000)\end{array}$ \\
\hline $\begin{array}{l}\text { No particular metaphor } \\
\text { used metaphor is essentially a way of under- }\end{array}$ & $\begin{array}{l}\text { Hirschheim } \\
\text { and } \\
\text { standing and experiencing one kind of } \\
\text { thing in terms of another. IS development } \\
\text { has been too narrowly conceived and the } \\
\text { use of symbolism will assist with moving } \\
\text { out of this very narrow focus. }\end{array}$ & $(1991)$ \\
\hline
\end{tabular}

A similar example is given using the "The Tower of Babel," which serves to reinforce the dichotomy between users and analysts. Beath and Orlikowski's examples illustrate that metaphors can be used to mislead and/or direct an organization in certain ways. In their analysis of a text on the participatory nature of IS design, Beath and Orlikowski discovered that "users seem to have little direct control over the nature and frequency of their contribution, the content and context of interaction, and the timing of events" (p. 361). The use of a particular metaphor excludes other meanings. Metaphors 
are also culturally and context specific. Boland (1987) identifies five metaphors which he feels guide systems development, but which are really dangerous fantasies "and not suited for guiding serious thought" as "they reify the human actor in ISD, and inevitably lead to dysfunctional consequences" (p. 367). The examples he gives are: Information as structured data, as an object or entity; organization is information; information is power; information is intelligence; and information is perfectible. Additionally, even though Kendall and Kendall (1993) endorse the use of metaphors by systems analysts, they conclude that in relation to practice, systems developers should be aware that users are enacting metaphors and this may guide the developer in choosing a methodology.

One of the other contemporary debates that the choice of the metaphor meraka is inextricably linked with is that of the open and free source debate. We briefly discuss this debate in the next section before describing the South African case study.

\section{THE OPEN SOURCE AND FREE SOFTWARE DEBATE}

Early writings on the FLOSS community frequently characterized (or caricatured) it as a hegemonic grouping with a common hacker culture (Raymond 1999). It is interesting, from the perspective of this paper, that Eric Raymond's important trilogy of papers made heavy use of metaphor to support his arguments: "The Cathedral and the Bazaar" (in which the proprietary software development model was contrasted to the bazaar-like approach ofFLOSS development) (Raymond1998b), "The Magic Cauldron" (which makes reference to the mythical Welsh Ceridwen's magic cauldron as an inexhaustible supply of creative plenty) (Raymond 2000), and "Homesteading the Noosphere" (likening the first appropriation of FLOSS projects to the frontier type practice of homesteading previously "unowned" land) (Raymond 1998b). This last image is actually quite a disturbing one in the context of FLOSS adoption in countries that were formerly colonies, where the historical colonial practice of homesteading has a far from positive connotation and the notion of "unowned" land simply reflected a disregard for all forms of land ownership which did not take the form of title deeds registered in a colonial deeds office. Nevertheless, Raymond's early writings played a vital part in starting off the process of understanding what was happening with this new FLOSS phenomenon. It was clear, whether one accepted Raymond's characterization or not, that by the end of the 1990s, FLOSS had established itself as being important, being of some value, and being potentially disruptive to the established models of creating software and doing business.

One of the more interesting fault lines in the global FLOSS "movement" is that between free software and open source software. It is possible to make too much of this divide as it can be argued that the difference is really a rather subtle one that has very little practical impact on the users of FLOSS. In most cases, the two alternative terminologies describe a broad intersection of essentially the same software.

"Free software" and "Open Source" describe the same category of software, more or less, but say different things about the software, and about values. The GNU Project continues to use the term "free software," to express the idea that freedom, not just technology, is important (Stallman 1999). 
The Free Software Foundation was founded by Richard Stallman and was built around the GNU GPL (general public licence). A large number of important software projects have been licenced under the GPL, including the gcc compiler (a necessary tool for compiling much of the FLOSS software in existence today), the linux operating system kernel, and the Gnome and KDE desktop management software. For Stallman, the notion of free software (that is free as in speech, not free as in beer) is a conscious attempt to politicize and create a movement.

Eric Raymond and Bruce Perens were founding members of the Open Source Initiative (OSI) in 1998, which popularized the term open source software (OSS). For the OSI, Stallman's notion of free software was obstructing the broader potential of FLOSS. The word free was ambiguous and would be viewed with suspicion by the corporate world. Raymond's "Cathedral and the Bazaar" trilogy made the case that OSS was technically a better way to produce software than the traditional "cathedral" style of proprietary software production. So whereas Stallman argues passionately that the collaboration and sharing that is an essential aspect of free software is a desirable goal in its own right, the OSI introduced a more instrumental justification: the collaborative and shared model of software development was to be encouraged primarily because it resulted in better software.

Reflecting back, in 2006, it is clear that FLOSS has continued to thrive and grow, attracting new groups of interest, not least of which have been large corporations such as IBM, Oracle, and HP and governments of developed and developing countries such as Brazil, India and South Africa. A consequence of this expansion has been the need to reflect upon the validity, legitimacy, and continued usefulness of the theories of early Raymondism. ${ }^{3}$ In a recent special issue of First Monday, Lin (2005) outlines the need for such a sociological reflection:

However, I argue that such a view, partially valid in explaining the FLOSS development, not only ignores the diversity of population and their different articulations, interpretation on and performances towards developing FLOSS, but also neglects the different environments and contexts where FLOSS is deployed, developed and implemented.

The phenomenon of FLOSS has also captured the attention of those working outside the field of computer software. There have been a number of efforts to conceive of FLOSS as part of a broader digital commons (see, for example, Boyle 1997). Boyle uses the concept of a commons as a metaphor to (1) highlight the case for different ownership models of so-called intellectual property and (2) to evoke a comparison with the period of Enclosures which characterized a rapidly industrializing Britain in the $17^{\text {th }}$, $18^{\text {th }}$, and $19^{\text {th }}$ centuries (Thompson 1963). Comparing the rapid expansion of the scope of copyright, patent, and trademark protection which marked the end of the $20^{\text {th }}$ century

${ }^{3}$ Raymondism is a term coined by Nikolai Bezrokov (see http:/ www.softpanorama.com) in which he describes the thinking behind "The Cathedral and the Bazaar" as an anarchic right-wing libertarianism or vulgar marxism. Raymond's reaction to being termed a marxist (vulgar or otherwise!) gave rise to a particularly vitriolic exchange between the two in the annals of First Monday. 
with this earlier period of enclosure is a theme which has also been picked by others including, for example, May (2000).

The idea of a commons is clearly a powerful metaphor for at least some aspects of FLOSS. In the Southern African context, there is no need to refer to a leafy image of "olde England" as all of the major indigenous languages have a rich vocabulary for describing various forms of commons land usage and management, many of which are still in common usage. After considering a number of options ${ }^{4}$ the seSotho word, meraka, was adopted as the symbolic name for the new FLOSS center.

\section{SOUTH AFRICAN CASE STUDY: OPEN SOURCE CENTER}

\subsection{Research Approach}

The case study of the CSIR's OSC was chosen for two reasons. First, two of the authors, as mentioned in the introduction, were closely linked with the center's formation in 2002 and its continued operation since. One of the authors is the manager of the center and the other was initially part of the setup team. Second, the remaining author has been investigating the use of metaphors as part of IS research strategies and all metaphors commonly found in the literature were Western. The conversation on how the use of an African metaphor was used in the naming of the OSC started after the manager of the OSC presented a guest lecture on open source software to postgraduate IS students.

The backgrounds of two of the authors - their lived experiences - were the main sources of primary data for the case study. A number of discussions were held between the three authors during which the history of the OSC was debated and traced. Often this necessitated the search for documentation of this history and further discussions so that agreement could be reached on the sequencing of events. Secondary data was obtained through the interrogation of documents and reports published by the OSC against this experience and background. Therefore, along with other interpretive researchers in the IS field (Lee 1994; Myers 1994; Walsham 1993), the position that our knowledge of reality is a social construction by human actions was adopted. In order to understand the origin of the metaphor used by the $\mathrm{OSC}$, an attempt was made to understand the meanings assigned to the metaphor and the context in which it was chosen.

A variety of stakeholders' opinions on their interpretation of the metaphor meraka was not sought, as the purpose of the case study and the data collected was to document the rationale behind the use of the metaphor. This was part of the authors' reflective

${ }^{4}$ For example, the Zulu word idlelo has approximately the same meaning as meraka. Idlelo was used as the title of the First Conference on the African Digital Commons held at the University of the Western Cape in January 2003. The Idlelo mailing list is still one of the most active lists dedicated to discussion of FLOSS issues on the African continent. The second Idlelo conference took place in Nairobi, Kenya, in February 2006. 
process on the establishment of the organization. Other interpretations of the metaphor, which may contradict or even encapsulate the meaning of the metaphor as described here, would be an interesting topic for further research.

\subsection{The OSC Case Study}

The OSC was formally launched in October 2003 by the CSIR and the Department of Science and Technology in the city of Tshwane, South Africa. The overarching objective in establishing the center was to stimulate the awareness, understanding, and optimization ofFLOSS benefits in Southern Africa, while contributing to similar efforts on the continent and the rest of the world. Part of the strategy for creating awareness and facilitating understanding of FLOSS is through developing and sustaining networks-consisting of members from government, industry, civil society, education, academia, and the open source community. The OSC works through three key areas: OpenSpeak, OpenMentor, and OpenProject.

- OpenSpeak focuses on developing partnerships, creating awareness, and providing information on FLOSS resources.

- OpenMentor aims to address the skills challenge by facilitating access to and development of learning and training materials for FLOSS.

- OpenProject intends to stimulate local adoption, adaptation, development, and testing of FLOSS.

The search for the name for the OSC was based on a number of factors or influences:

- the difficulty in explaining FLOSS

- the OSC had to appeal to a broad African audience, including policy makers, members of the government and the general public

- awareness that the common property relations implicit in FLOSS licences resonated with the familiar concepts of communal land and water rights on the African continent

After a brainstorming session and a number of wide-ranging discussions with a broad audience, the OSC adopted the name Meraka because it captures the notion of collective property rights, development, and collaboration within Southern Africa that is consistent with the FLOSS philosophy.

FLOSS is very much like a digital meraka. Unlike most proprietary software, open source software is available at little or no cost. The inner workings of FLOSS are also available to all who want to see it and use it. Unlike proprietary software, the source code for an open source software application is not a closely guarded secret of any individual or organization. The open and free availability of the source code allows and encourages a model of development, testing and modification based on public collaboration. 


\section{DISCUSSION}

Within a year of the OSC being established at the CSIR, the ICT related units of the organization underwent a substantial restructuring. The fledgling African Advanced Institute for Information and Communication Technologies (AAIICT) initiative was revived under the name of the Meraka Institute and the OSC was incorporated within this institute.

Whereas the use of the metaphor meraka had supported the aims of the OSC in a number of ways, the metaphor now contributed to the broader South African transformation drive by getting people to see themselves as bamerakeng ${ }^{5}$ and not just members of yet another entity with an English name. One example of the effectiveness of this is the recent signing of an agreement with the United Nations Development Programme (UNDP). The agreement develops the strategy on how to boost the open source capacity for the region through a knowledge networking project. By selecting an indigenous institution such as the Meraka Institute to be the implementing agency, the UNDP hopes to encourage South-South cooperation ${ }^{6}$ and extend the benefits of the project to the rest of the continent.

Simultaneously the metaphor allowed the organization to affirm its position with regard to the digital commons. Beyond the South African situation, the use of indigenous metaphors has also found acceptance within the African continent, where the concept of communal land and ownership still plays an important part in peoples' lives. The idlelo mailing list, for instance, has continued to grow. The Kenyans even introduced the concept of Kiwanja, which is the kiSwahili translation of Idlelo and Meraka. Various contributors to the idlelo mailing list have also used a range of metaphors in their projects and reports. These include the various African names for gnu/linux distributions like Mambo, Impi, and Ubuntu. The Asiasource report (Noronha 2005) uses many metaphors. In this way, the term has opened up a wider discussion on how our countries are connected through a common culture, and how we can collaborate in the open source arena-opened up the discussion in the region.

Meraka has enabled people to draw a meaningful line between lessons from the agricultural age and challenges of the knowledge age. In a country where both realities still exist, this is important. This was well illustrated during a live radio broadcast by Jozi FM that was done in support of the Software Freedom Day activities in Soweto. The timing of the event coincided with a program focusing on traditional music. Some of the folk songs and poetry that were aired during this program resonated with the FLOSS celebration that was taking place. The intermittent interviews that took place with various "geeks" reaffirmed this connection. During one of the interviews, the idea of extending the Translate ${ }^{7}$ project into local slang known as tsotsitaal was investigated. The host of the show summed it up at the end by pointing out that the program was more successful because it combined popular traditional folklore with leading edge technology phenomena like free software.

${ }^{5}$ Directly translated as "the people of meraka."

"South-South" is a term commonly used to denote relations between developing countries (which are mostly, but not always, in the South), as distinct to partnerships between developing and so-called developed countries.

${ }^{7}$ Translate.org.za aims to make free software available in local languages. 
In summary, the use of the metaphor meraka has enabled the articulation of thinking behind the concept of free software without being caught up in the free/open source debate. It has also allowed for a demonstration of the broadness and depth of the thinking behind some of the related initiatives. Consequently it has become relatively easy to extend the concept beyond software to other important aspects of the digital commons.

However, there has also been some resistance. As Young (1989) showed in his analysis of the meanings of the rose in an organization, the metaphor meraka may not be viewed in the same way by all members in the CSIR. Although people readily warm up to the name when they understand what it means, there were problems with the initial association of common grazing land with a cattle post. However, this is soon resolved when people get to see the name in the context of the organization. Additionally there was also some concern over the "Africanness" of the name of the organization. For example, the term marakas meaning chaos or a shambles in Afrikaans is the name given to the organization in the corridors by some members of the organization.

In general, though, there have been positive benefits from the use of the metaphor. Along with those listed above, we conclude with one example where the metaphor assisted in lobbying the much needed political support and "buy-in" from the government. At the launch of the Meraka Institute, the Minister of Communications explained the name by articulating the vision of a free, shared digital commons:

I am proud to formally announce that this institute will be known as the Meraka Institute. The name is a Sesotho word which has different interpretations, but in this instance relates to a common space that is shared by a community for creative and productive activity (Minister of Communication 2005).

\section{CONCLUSION}

This paper shows how using an indigenous metaphor played an important role in the transformation process of a FLOSS organization in South Africa. In line with the traditional use of metaphors, the use of the term meraka helped align the organization with the broader transformational issues taking place in South Africa.

Additionally, most of the literature on metaphors relies on Western concepts and philosophy. This paper shows the potential role that indigenous metaphors can play. The use of a Southern African concept of communal land and the metaphor meraka shows how metaphors can make it easier to understand in that context and help bridge the divide between everyday life and the more technical aspects of life. The metaphor also has wider implications; it illustrates how in this case it assists with overcoming some of the global issues around free and open software, which is fundamentally rooted in a Western conception of property that is ill-suited for FLOSS.

An important characteristic of the debate between Stallmanism and Raymondism is that, despite appeals in both cases to universal values, there is something peculiarly American about it all. In the "land of the free," the terms free and freedom appeal to a strong vein of identity within that nation's psyche. Referring back to Lin's suggestion of the need for sociological reflection, debates about whether one form of licence is 
more free than another do not resonate in the same way with a South African society, which has its own very powerful tradition of interpretation of, and struggle for, freedom. We are left with a sense that, whereas the social values emphasized by Stallman (and deemphasized by the open source approach) are a significant factor in the potential attractiveness of FLOSS as a tool for development and growth in South Africa, there is a need to reimagine, to reinterpret, and perhaps to "re-vocabularize" these powerful ideas to better integrate them with both our tradition and our projected development trajectory. We find ourselves almost entirely in agreement with Stallman, and even grudgingly respectful of Raymond - we simply believe that we can, and should, find better words which better express the meaning and potential of FLOSS according to our own image.

\section{References}

Allen, J., and Lientz, B. P. Systems in Action, Santa Monica, CA: Goodyear Publishing Company, Inc., 1978.

Arntzen, J. W. Environmental Pressure and Adaptation in Rural Botswana, unpublished $\mathrm{PhD}$ Thesis, Vrije Universiteit te Amsterdam, 1989.

Beath, C. M., and Orlikowski, W. J. "The Contradictory Structure of Systems Development Methodologies: Deconstructing the IS-User Relationship in Information Engineering," Information Systems Research (5:4), 1994, pp. 350-377.

Boland, R. "The In-Formation of Information Systems," in R. Boland and R. A. Hirschheim (eds.), Critical Issues in Information Systems Research, Chichester, UK: John Wiley \& Sons, Inc., 1987, pp. 363-379.

Boyle, J. "A Politics of Intellectual Property: Environmentalism for the Net?," Duke Law Journal (47), 1997, pp. 1, 87-116.

Gallupe, R. B. "Images of Information Systems in the early $21^{\text {st }}$ Century," Communications of the AIS (3:3), 2000.

Hirschheim, R. and Klein, H. "Four Paradigms of Information Systems Development," Communications of the ACM (32:10), 1991, pp. 1199-1216.

Hirschheim, R., and Newman, M. "Symbolism and Information Systems Development: Myth, Metaphor and Magic," Information Systems Research (2:1), 1989, pp. 29-62.

Kendall, J. E., and Kendall, K.E. "Metaphors and Methodologies: Living Beyond the Systems Machine," MIS Quarterly (17:2) June 1993, 149-171.

Krefting, L. A., and Frost, P. J. "Untangling Webs, Surfing Waves, and Wildcatting: A Multiple-Metaphor Perspective on Managing Organizational Culture," in P. J. Frost, L. F. Moore, M. Louis, C. C. Lundberg, and J. Martin (eds.), Organizational Culture, Thousand Oaks, CA: Sage Publications, 1995.

Lakoff, G., and Johnson, M. Metaphors We Live By, Chicago: University of Chicago Press, 1980.

Lee, A. S. "Electronic Mail as a Medium for Rich Communication: An Empirical Investigation Using Hermeneutic Interpretation," MIS Quarterly (18:2), June 1994, pp. 143-157.

Lin, Y. "The Future of Sociology of FLOSS," First Monday, Special Issue \#2: Open Source, October 32005 (available online at http://firstmonday.org/issues/special10_10/).

Madsen, K. H. "Breakthrough by Breakdown: Metaphors and Structured Domains," in H. K. Klein and K. Kumar (eds.), Systems Development for Human Progress, New York: North Holland, 1989, pp. 41-53.

Mangham, I. L., and Overington, M. A. Organizations as Theatre: A Social Psychology of Dramatic Appearances, Chichester, UK: John Wiley \& Sons, 1987. 
Mason, R. M. "Metaphors and Strategic Information Systems Planning," in J. Nunamaker, Jr. and R. H. Sprague, Jr. (eds.). Proceedings of the Twenty-Fourth Annual Hawaii International Conference on Systems Sciences (Volume 4), New York: Plenum Publishing, 1991, pp. 231-240.

May, C. A Global Political Economy of Intellectual Property Rights, London: Routledge, 2000.

Minister of Communications. Keynote address by the Minister of Communications at the launch of the Meraka Institute, May 17, 2005 (online at http:/www.meraka.org.za/).

Morgan, G. Images of Organizations, Beverly Hills, CA: Sage Publications, 1986.

Myers, M. D. "A Disaster for Everyone to See: An Interpretive Analysis of a Failed IS Project.," Accounting, Management and Information Technologies (4:4), 1994, pp. 185-201.

NACI (National Advisory Council on Innovation). "Open Software and Open Standards-A Critical Issue for Addressing the Digital Divide," 2002 (online at http://www.naci.org/).

Noronha, F. "Opting for a Week on the Wrong Side of the Digital Divide," Tactical Technology Collective, 2005 (online at http://www.africasource.org/).

Ott, J. S. Organizational Culture Perspectives, Chicago: Dorsey Press, 1989.

Oxford Advanced Learner's Dictionary ( $4^{\text {th }} \mathrm{ed}$.), Oxford, UK: Oxford University Press, 1989.

Pondy, L. R. "The Role of Metaphors and Myths in Organization and the Facilitation of Change," in L. R. Pondy, P. J. Frost, and T. D. Dandridge (eds.), Organizational Symbolism, Greenwich, CT: JAI Press, 1983, pp. 157-166.

Ramiller, N. C. "Airline Magazine Syndrome: Reading a Myth of Mismanagement," Information Technology and People (14:3), 2001, pp. 287-303.

Raymond, E. S. "A Brief History of Hackerdom," in C. Di Bona, S. Ockman, and M. Stone (eds.), Open Sources: Voices from the Open Source Revolution, Sebastopol, CA: O' Reilly and Associates, 1999.

Raymond, E. S. "The Cathedral and the Bazaar," First Monday (3:3), March 1998a (available online at http://www. firstmonday.org/issues/issue3_3/raymond/index.html).

Raymond, E. S. "Homesteading the Noosphere," First Monday (3:10), October 1998b (available online at http://www.firstmonday.org/issues/issue3_10/raymond/index.html).

Raymond, E.S. "The Magic Cauldron," Version 3.0, 2000 (available online at http://www.catb.org/ esr/writings/cathedral-bazaar/magic-cauldron/).

Stallman, R. "The GNU Operating System and the Free Software Movement," in C. DiBona, S. Ockman, and M. Stone (eds.), Open Sources: Voices from the Open Source Revolution, Sebastopol, CA: O'Reilly and Associates, 1999.

Thompson, E. P. The Making of the English Working Class, New York: Penguin Books, 1963.

Walsham, G. Interpreting Information Systems in Organizations, Chichester: Wiley and Sons, 1993.

Weaver, R. M. A Rhetoric and Handbook, New York: Holt Reinhart and Winston, 1967.

Young, E. "On the Naming of the Rose: Interests and Multiple Meanings as Elements of Organizational Culture," Organization Studies (10:2), 1989, pp. 187-206.

\section{About the Authors}

Elaine Byrne is a senior lecturer at the Department of Informatics, University of Pretoria. She recently obtained her doctorate from the University of the Western Cape, Cape Town, South Africa, in Public Health on the design and development of community based health information systems. Her general research interest areas are information systems and social development, qualitative research methodology, and health information systems. Elaine may be contacted at elainebyrne@up.ac.za.

Bob Jolliffe is a senior lecturer in Computer Science at the University of South Africa, where he completed his M.Sc. in 2002. He is actively involved in the Free/Open Source 
Software movement in South Africa. His current research is directed toward the effects of the patent system on innovation in computer software in developing countries. Bob may be contacted at jollirm@unisa.ac.za.

Nhlanhla Mabaso has worked in a range of ICT areas. After completing his B.Sc. (Computer Science and Applied Maths) at the University of the Witwatersrand, he worked as a software engineer for an airline. He later took on other responsibilities as a systems analyst for an Internet service provider working on a range of areas including systems administration, Internet hotline, online databases as well as strategic consulting. By the time he completed his Master's in Business Administration studies, he had moved into the area of management within the private and later he public sector where he was Chief Information Officer. He is currently involved in the Meraka Institute's Open Source Centre initiative hosted at the CSIR. All this work has necessitated the establishment of a wide range of local and international partnerships, with partners from within Africa, Brazil, China, Finland, the European Union, and India. He is currently the coordinator of the Free Software and Open Source Foundation for Africa (FOSSFA). Nhlanhla may be contacted at nmabaso@csir.co.za. 